\title{
Addressing the Tensions and Controversies towards Quality Science Education: A Pragmatic Approach
}

\author{
John F Kalolo (PhD) \\ Faculty of Education, Mkwawa University College of Education \\ Iringa, Tanzania \\ E-mail: mwakalolo@yahoo.ca
}

Received: March 29, 2015 Accepted: April 17, 2015 Published: June 2, 2015

doi:10.5296/iss.v3i1.7345 URL: http://dx.doi.org/10.5296/iss.v3i1.7345

\begin{abstract}
Quality science education (SE) has emerged in the last few years as a necessary requirement for a specific country to advance technologically, develop literate scientific community, and improve the country's competitive power. As such critical commentaries have surfaced on how SE can be best provided in schools. In the context of Tanzania the concerns towards quality SE seem to be mounted, but with little achievements as a result of a slanted definition of the term quality SE. Such biased explanation about quality SE has led to several tensions and controversies in its practice. This paper examined stakeholders' views about the meaning, measurement, and goals for providing quality SE in Tanzanian Junior secondary schools (JSS). In particular, the paper was focused on understanding what SE stakeholders consider quality SE is, how it is measured, the goals for its delivery, and the implications for all these. The study involved 100 SE stakeholders in the categories of students, teachers, and heads of schools, science alumni and parents. The paper presents useful information for SE researchers, students, and policy makers that is likely to help them appreciate some unanswered questions about quality SE and reflect on new commitments in the provision of quality SE, and guide the continued discussion and ongoing conversation about promising ways to understanding, describing and providing quality SE in schools.
\end{abstract}

Keywords: science education, quality, pragmatism, controversies, quality science education 


\section{Introduction}

Quality SE is identified in the literature as a complex and multi-faceted concept Hakielimu, 2007; Knipprath, 2010; Ogunmade, 2005). Internationally the recent discussion has focused around what is meant by quality SE and envisioning how to achieve it on national and local levels. While it is relatively easy to spot the indicators of quality SE, some literatures identify that it is difficult to not only define it but also unrealistic to claim for a universal definition about quality SE that would apply to all situations (Green, 1994; Motola, 2001; Tikly \& Barret, 2007).

The illusiveness of the concept of quality SE has led to most understandings and descriptions about quality SE being much divided all over the world. Debates about the meaning of quality SE have identified the concept of quality SE in terms of several different views including: Institutional mechanisms, enrolments and performance of science students at different levels, the quality and number of science teachers, infrastructural facilities' availability, and the practical relevance of science curricular.

UNESCO (2005) identifies quality education in terms of its ability to strengthen the instrumental roles of schooling, such as helping individuals achieve their own economic, social and cultural objectives. This involves a process of maximising the schools' systems performance and ability to: (i) Prepare students for the adult role as citizens; (ii) Train them to fulfil an appropriate adult role; (iii) Develop personality, especially inter-personal skills; (iv) Remove the recipient from an unemployed status. The emphasis about quality science education (SE) in today's world seems to be hinged in very diverse and quite different emphases in practice. The differences in emphasis are resulted from the confusion in an attempt to answer the following quality related questions: What is worthy learning and teaching? What should be emphasized over the other? What are the criteria for judging quality SE? Quality SE for whom? Why should we bother providing quality SE in schools?

In an attempt to address what quality education is and how should look like, many scholars such as Sallis (2002), Sifuna (2007), and Sumra and Rajani (2006) have invested years in trying to understand how quality education looks like and envisioning how to achieve it at global, national and local levels. Despite their attempts to define it, various controversies still remain (SACMEQ, 2005).

In such diverse and dilemmatic situation regarding its meaning, it is clear that the understanding of quality SE using a universal meaning and emphases is unrealistic. As such, a development of a new approach to understanding the concept of quality SE is inevitable. It should however be understood that an attempt to address the controversies regarding quality SE in Tanzanian secondary schools as identified in this paper is not a new attempt; qualms have been voiced by other authors including Chonjo, Osaki, Possi and Mrutu, (1996), Osaki, Hosea, and Ottevanger, (2004), and Hamilton, Mahera, Mateng'e, and Machumu, (2010). In the context of this paper a concern is taken to understand the SE stakeholders' views regarding quality SE, particularly a concerted effort is taken to identify promising ways to describing the meaning, measurement and goals of quality SE. 


\section{MInstitute Macrothink $^{\text {Int }}$}

Issues in Social Science

ISSN 2329-521X

2015, Vol. 3, No. 1

The premise held in this paper is built on the question whether is realistic to view quality SE as an absolute, simple, unambiguous, or unitary concept. It is from this line of view that, the researcher felt the responsibility of debating about it, looking to solve the dilemmas, and finding out how the concept could be appropriately addressed in practice. While bearing in mind the needful desire to produce a meaningful definition of quality SE, the researcher was aware of the challenge ahead which is to make sure that concerted efforts are in place to illustrate the complexities and ambiguities of the concept with the aim of solving them.

\section{The Pursuit of SE in Tanzania}

The pursuit of SE and the aspirations of young learners towards careers in science vary greatly between countries and regions (OECD-GSF, 2006). This is due to the differences in the way SE is structured, practised and evaluated. While other countries have different structures for SE, the training of Tanzanian students in science begins at Standard 3 (or Year Three) in primary school and its content advances along with the level of education. In Tanzanian primary schools, science is learnt as "integrated science" where learning is limited to basic concepts in the core disciplines of biology, chemistry and physics. Science subjects in secondary schools are learnt in the form of "single subject matter" whereby biology, chemistry, physics and mathematics are taught separately, and grouped in triplicate they form science combinations. The four subjects are compulsory for all students up to Form 2 (year two of secondary education) but they may be optional subjects during Form 3 for those majoring in arts, and commerce.

The nature of today's SE in Tanzania is a result of the interaction between two different cultures: western culture and the African-Tanzanian culture. The interaction and balance between these two epistemologies determine how science is planned, practiced, evaluated and monitored in today's Tanzanian JSS. According to Osaki (2002) the status of SE in Tanzania has been influenced by three main political influences: traditional heritage, colonial heritage and post-colonial heritage. Traditionally SE aimed to inculcate indigenous cultural heritage from one generation to another. This kind of education was free from western influences and its purpose was to enable people to solve specific local problems. This form of education changed during the colonial periods to a colonial type education, as pioneered by Germany (1880s - 1920s) and the British (1920s-1960s).

Osaki (1995) contends that colonial education was designed not only to invalidate traditional science knowledge by inculcating western science knowledge at the expense of traditional science, but to also create the demand for western science and technology. While during the post-colonial period there were a few notable efforts to contextualise SE practices for the sake of addressing specific Tanzanian challenges, such efforts have achieved little success to date due to the continued positioning of western science as superior wisdom (Osaki, 1994; Osaki, Ottevanger, Uiso, \& van den Akker, 2002)

In recent decades the quality and relevance of Tanzanian SE has initiated public outcries about its irrelevance, dysfunctionality, and context irresponsiveness (Hakielimu, 2007; Hamilton et al 2010). The emergence of these complaints is attributed to the fact that the SE system has failed to make the learner self-reliant in their life endeavours. As such, it is 
possible that the quality of SE in todays' Tanzanian JSS has a lot to do with the colonial experiences the Tanzanian education system has gone through and the way quality SE as a concept is perceived and understood.

\section{The Desire to Provide Quality SE in Tanzanian Secondary Schools}

Similar to other countries, the desire to provide quality SE in Tanzania is driven by complex and conflicting variables that feature rapidly growing transformations marked by new discoveries and progress in all spheres of human activity, including economic, social, cultural and political (Bull, Gilbert, Barwick, Hipkins, \& Baker, 2010; Munro \& Elsom, 2000; OECD-GSF, 2006). One notable consequence of these transformations is the pressure to redefine the secondary school SE practices to enable citizens to deal with the challenges in the modern world.

Drawing from this ambition it is an aspiration of most, if not all, developing countries including Tanzania to make sure that the SE provided in schools is contextually relevant and functional for students in solving the challenges they encounter in life (OECD-GSF, 2006; Ogunniyi, 1986). However such ambition is confronted by the divided views towards what quality SE entails. Such a situation is stated to have a negative impact towards successful delivery of science knowledge and skills needed for the scientific and technological development of those countries (Ogunniyi, 1986; OECD-GSF, 2006; Osaki, et al., 2004).

The divided views and controversies towards provision of quality SE in most countries has also led to the development of conceptually weak policies, science curricula and poor pedagogical and assessment strategies (Bybee, 2010; Hamilton et al 2010; Munro \& Elsom, 2000). Similar example of the impact of controversies towards quality SE include those identified by Chonjo et al (1996), Galabawa (1994), Mushashu (1997; 2000) and Osaki, et al., (2002) who assert that since independence Tanzanian education has been characterised by overloaded syllabi, a high level of content abstraction, and the teaching of facts which are largely irrelevant to the Tanzanian context. This situation has increased pressure on most developing countries, including Tanzania, to prioritise quality and relevant SE (Roth \& Lee, 2004; UNESCO, 2008).

Though the problems in SE have become more critical and have been extensively debated over recent decades, very little has been achieved in making it more functional and relevant to Tanzanian learners (Chonjo, et al., 1996; Kitta, 2004; Osaki, et al, 2004). Evidence shows that continuous efforts to assist Tanzania in improving SE have largely failed to meet the goals of equipping the students with the appropriate knowledge and skills to meet challenges in agriculture, health, industry, housing, transport, and communication (Ottevanger, et al., 2005; Osaki et al, 2002). Along with this Tanzania has witnessed mass failures in the JSS national examinations. For example, the National Form 4 Examination results in 2004, 2005 and 2006 saw high failure rates in Mathematics, at 70\%, 77\% and 76\% respectively.

An important factor in the failure to achieve quality SE in Tanzanian JSS is related to the way SE is understood, practiced and evaluated. But also the situation of SE in today's Tanzanian JSS is attributed to assistance offered by western countries whose support has largely been to 
transfer forms of SE practices that are seen as "ideally working" in the developed world without any test for their practicability, credibility and desirability, or sustainability within the specific context of developing countries (Mafumiko, 2004; Ministry of Education and Culture (MoEC), 2004; Kitta, 2004; Osaki \& Tilya, 2004). These Eurocentric perspectives have prevailed due to the absence of critical views about the SE frameworks in practice that would have served as contextual alternative working frameworks to improve SE in Tanzanian JSS. As a result, the practices in SE have been swayed away, misdirected and led to unfruitful fate.

\section{Methodology}

This study was largely a qualitative study focused at understanding how the stakeholders understood and described the concept of quality SE in Tanzanian JSS. The study was carried out in Tanzania involving a total of 100 respondents in the categories of students, teachers, and heads of schools, science alumni and parents. The population sample was obtained through stratified, simple random and purposive sampling procedures when it was necessary. Data was collected through questionnaires, interviews, focus group discussions and documentary review. Data were largely analysed qualitatively through thematic analysis and presented descriptively.

The study was driven by the awareness that: Providing quality SE is a joint task that involve a number of stakeholders who are likely to have different views on how to articulate, practice and measure it. The study acknowled ges that different approaches have been employed in the previous efforts to understand and describe what quality SE is, all of which had little success, a situation which demands re-examination of the concept to produce a promising framework or model for understanding and describing quality SE.

\section{Findings}

The findings of the present study reveal a range of views regarding quality SE and that despite being from similar contextual educational experience; the respondents had different views about quality SE. This situation makes the concept of quality SE even more elusive, complex and challenging to define.

The findings revealed that although there was some agreement among respondents on the way they understood quality SE, largely there were disagreements regarding what quality SE was. The difference in respondents' views indicated that their views were determined by their particular interest in SE and the stakeholders' groups in which they belonged. For example, quality SE was understood differently by the stakeholder groups in that:

- Parents felt that quality SE should enable the learner to acquire necessary skills for future employment;

- Science Alumni were in agreement with parents in that they wanted students to acquire skills and knowledge for future employment and also to become responsible citizens;

- Science teachers and the heads of schools believed quality SE in JSS needed to prepare students for higher education and for future careers in science; 
- The students wanted quality SE to help them pass exams, continue to higher levels, and be successful in the future;

- Science alumni and teachers were in agreement that quality SE needed to be context responsive, relevant to the learners' lives, functional and applicable to the learners after graduation

Quality SE in this particular case is therefore identified as a relative concept, in the sense that its meaning and descriptors are relative to the particular context, type of respondents involved, and their needs. Such diverse and divided views about quality SE are likely to have some limitations towards success of providing quality SE in schools, an outcome necessary to preparing Tanzanian students to confidently face the social and economic demands of today's world. Table 1 summarises the questionnaire responses completed by all respondents regarding their views towards quality SE.

Table 1. Summary of respondents' views on how they understood quality $\mathrm{SE}(\mathrm{N}=100)$

\begin{tabular}{|c|c|c|c|c|c|c|c|c|c|c|c|c|c|c|c|c|}
\hline \multirow{3}{*}{$\mathrm{C} / \mathrm{N}$} & \multirow{3}{*}{$\begin{array}{l}\text { Quality science } \\
\text { education descriptor }\end{array}$} & \multicolumn{12}{|c|}{ Respondents views (\%) } & & & \\
\hline & & \multicolumn{3}{|c|}{$\begin{array}{l}\text { Policy } \\
\text { makers }\end{array}$} & \multicolumn{3}{|c|}{$\begin{array}{l}\text { Science } \\
\text { educators }\end{array}$} & \multicolumn{3}{|c|}{$\begin{array}{l}\text { Science } \\
\text { alumni }\end{array}$} & \multicolumn{3}{|c|}{ Parents } & \multicolumn{3}{|c|}{ Average $(\%)$} \\
\hline & & A & $\mathrm{N}$ & $\mathrm{D}$ & A & $\mathrm{N}$ & $\mathrm{D}$ & A & $\mathrm{N}$ & $\mathrm{D}$ & A & $\mathrm{N}$ & $\mathrm{D}$ & A & $\mathrm{N}$ & $\mathrm{D}$ \\
\hline \multirow[t]{2}{*}{1} & Meeting stakeholders & & & & & & & & & & & & & & & \\
\hline & expectations & 25 & 61 & 14 & 97 & 1 & 2 & 90 & 1 & 9 & 36 & 53 & 11 & 62 & 29 & 9 \\
\hline \multirow[t]{2}{*}{2} & Development of & & & & & & & & & & & & & & & \\
\hline & students'potentials & 92 & 4 & 4 & 76 & 9 & 15 & 82 & 8 & 10 & 78 & 7 & 15 & 82 & 7 & 11 \\
\hline \multirow[t]{2}{*}{3} & Providing quality school & & & & & & & & & & & & & & & \\
\hline & experiences for students & 68 & 23 & 9 & 92 & 0 & 8 & 90 & 10 & 0 & 70 & 11 & 19 & 80 & 11 & 9 \\
\hline \multirow[t]{2}{*}{4} & Provision of good & & & & & & & & & & & & & & & \\
\hline & learning support services & 83 & 0 & 17 & 96 & 0 & 4 & 89 & 1 & 10 & 76 & 15 & 9 & 86 & 4 & 10 \\
\hline \multirow[t]{2}{*}{5} & Determinant of the & & & & & & & & & & & & & & & \\
\hline & learners' future life & 57 & 9 & 34 & 52 & 14 & 34 & 67 & 10 & 23 & 72 & 3 & 25 & 62 & 9 & 29 \\
\hline \multirow[t]{2}{*}{6} & Achievement of good & & & & & & & & & & & & & & & \\
\hline & grades in the final exams & 72 & 3 & 25 & 57 & 10 & 33 & 52 & 14 & 34 & 67 & 9 & 24 & 62 & 9 & 29 \\
\hline 7 & Sufficient T/L Resources & 64 & 26 & 10 & 80 & 12 & 8 & 86 & 14 & 0 & 62 & 20 & 18 & 73 & 18 & 9 \\
\hline 8 & Creed for excellence & 82 & 2 & 16 & 72 & 11 & 17 & 64 & 26 & 10 & 55 & 30 & 15 & 67 & 19 & 14 \\
\hline 9 & $\begin{array}{l}\text { Achievement of an } \\
\text { educational goal }\end{array}$ & 92 & 0 & 8 & 58 & 36 & 6 & 91 & 1 & 8 & 45 & 37 & 18 & 72 & 18 & 10 \\
\hline 10 & $\begin{array}{l}\text { Good SE leaders and } \\
\text { managers. }\end{array}$ & 91 & 0 & 9 & 87 & 3 & 10 & 88 & 4 & 8 & 86 & 1 & 13 & 88 & 2 & 10 \\
\hline 11 & Good science teachers & 87 & 6 & 7 & 95 & 0 & 5 & 88 & 1 & 11 & 87 & 6 & 7 & 89 & 3 & 8 \\
\hline 12 & $\begin{array}{l}\text { Human capital } \\
\text { investment }\end{array}$ & 65 & 2 & 33 & 83 & 3 & 14 & 93 & 0 & 7 & 73 & 0 & 27 & 79 & 1 & 20 \\
\hline 13 & $\begin{array}{l}\text { Supportive Learning } \\
\text { Environment. }\end{array}$ & 64 & 29 & 7 & 88 & 2 & 10 & 78 & 8 & 14 & 89 & 3 & 8 & 80 & 10 & 10 \\
\hline
\end{tabular}

Key=======>> $>$ A =Agree; $\mathrm{N}=$ Not sure; $\mathrm{D}=$ Disagree; $\mathrm{T} / \mathrm{L}=$ teaching and learning 
Overall, the questionnaire and interview data showed that the stakeholders' views about quality SE were framed around the following:

i. A creed of excellence for the education system. Most respondents especially policy makers and science educators described quality SE in terms its ability achieve the specific set of standards (norms and societal values) that are used to shape individual and institutional performances. Though parents and science alumni placed little importance on the idea of excellence being the descriptor for quality SE, most respondents felt that quality SE has partly some attributes of excellence under which SE status, and standards, and the health of the SE system can be judged.

ii. As a positive transformational change. Quality SE was viewed by the majority as an incremental process or a transformative change that takes an individual learner from one level of understanding to another. This change involves moral and socio-cognitive change, attitude enhancement and students' empowerment through enhanced learning competencies and development of students' potentials. Most respondents especially policy makers identified quality SE as being related to the whole transformation of a learner's potentials. These potentials include: expertise in science subjects, confidence, the determination to do well, and having the will power to make informed decisions.

iii. As the achievement of an educational goal. Quality SE was mostly described by policy makers and science alumni in terms of its ability to achieve the educational goals which include ensuring that the needs of individual learners are met and that there is greater satisfaction with education provided in the nation at large. Within this view, policy makers and science alumni described schools as centres that not only function according to their mission statements in the production of individuals with critical minds, but also make it possible for all education processes to work towards meeting the desired educational goals. Science educators and parents shared a view that, though achieving the educational goal is important; it was not a sufficient descriptor for quality SE.

iv. Stakeholders'satisfaction. Though policy makers and parents placed little importance on the requirement of quality SE to meeting stakeholders' expectations the majority of respondents especially science educators and science alumni viewed quality SE as an educational outcome that is judged on its ability to satisfy the stated or implied needs of the stakeholders and meet or exceed the stakeholders' requirements and expectations. Within this view, schools were identified as being responsible for satisfying the learners' interests, helping them to meet their desired expectations and nourishing and nurturing passion in science.

v. Learners'future life determinant. Quality SE as future life determinant for the students was more plausible to science alumni and parents than others. One student said "quality SE is a determinant of graduates' futures, their employability, their future prospects, and their productivity in society after completion of their courses". In the same line of view another student said "quality SE could be looked at a relationship between what students gain as a result of schooling and the ability of schools to meet 
students' expectations and their aspirations to develop their preferred professional identities". Though policy makers and science educators identified little link between quality SE and the learners futures, most of them were in agreement that quality SE had to be the one that prepares learners for active participation in the broad range of work and community activities affecting the quality of their lives and the lives of those around them.

vi. Human capital investment. Science educators and science alumni shared the view that quality SE was a function of resource investment both physical educational resources or facilities, and human resource. Though other groups of respondents did not have high agreement on human capital investment being a descriptor of quality SE, most of respondents considered the amount of investment in education as partly having a the power to determine the strength of a particular education system and the type of workforce to be produced. One science alumni said "it is important to allocate more resources in the education sector through funding the human resource development programs because such initiative is likely to increase social and human capital in the society in which students live”.

vii. Quality School Experiences for Students. Quality SE was described by most science educators and science alumni as quality school experiences including what students learnt at school, how they learnt, and what benefits students drew from their education. In the interviews, more than $90 \%$ of the se groups of respondents related quality SE to being able to provide learning experiences that lead to academic gain in science subjects, as well as attitudinal and value change amongst students. It was clear from most respondents that quality SE experiences should provide a sense of fulfilment among learners, and the satisfaction that they had received a quality educational experience from their schooling. Most respondents felt that it was not just about students achieving their potential but also about the school providing rich learning experiences. The purpose, in their view, was not to alienate students from society but to develop new perspectives on life through their school experiences.

viii. Good Learning Support Services. More than $85 \%$ of respondents especially science educators and science alumni described quality SE in terms of the availability and adequacy of students' learning support services. Examples of learning support services include weekly study skills workshops, study groups, homework help sessions for selected courses, after school academic teaching, accommodation support for students with disabilities, and the availability of study skills consultation. While some other categories of respondents such as parents placed little importance on this aspect the majority of them related quality SE to the availability and quality of guidance and counselling services that would enabled students to make informed decisions about future science careers and the availability of well-equipped and up-to-date libraries and laboratories to facilitate student learning.

ix. Good Grades in the Final Examinations. Unlike policy makers and parents who described quality SE in terms of students' achievements in the national examinations; 
science alumni and science teachers placed little importance on the grades in the final examinations as descriptors for quality SE. Different to the view by most science alumni, one parent said that "quality $S E$ is everything about gaining good grades in their final exams". Most respondents attributed the achievement of high exam grades to a better education system in their schools. However all respondents appeared to believe that quality SE was partly reflected in high examination achievement. Although they differed on the link between grades in final examination and the quality of education offered most of them felt that the achievement of good grades in the national examinations has a lot of implications on the credibility of the academic certificates, the standard of education offered, the competitiveness of the graduates to secure good jobs, and the mental capability of the individual graduate.

x. Sufficient Teaching and Learning Resources. The majority of science educators and science alumni highly identified the availability of sufficient and relevant teaching and learning resources as being important component of quality SE. They identified these teaching and learning resources to include the availability of; science textbooks, (students' books and teacher guides), qualified, competent, caring and motivated teachers and educational managers, and the availability of teaching and learning aids (textual, visual and audio-visual materials). Despite the difference of importance attached to this category as a descriptor for quality SE, one science alumni said that "availability of teaching staffs, learning support staffs and the teaching and learning materials were important in making learning effective".

xi. Supportive Learning Environment. Though some other respondents were uncertain about learning environment being an important component of quality SE; science educators and parents described supportive and conducive learning environment as being important descriptor foe quality SE. The most mentioned aspects of supportive and conducive learning environment included the physical learning environment (manageable class sizes that support collaborative learning), an intellectual learning environment that stimulates students to think, and an emotional learning environment where students can feel safe, supported, respected, disciplined and motivated to learn. Despite the difference on the importance attached to this quality descriptor, the majority of respondent held the view that quality SE partly depicts a highly supportive learning environment where students feel comfortable, connected with their learning process, their instruction personalised and the one that allows students to take responsibility for their own learning, take learning risks, and express themselves.

xii. Good SE leaders and managers. Good educational leadership was described as a desirable component of quality SE by the majority of respondents. More than $85 \%$ of respondents shared the view that possession of relevant, competent leadership skills, and educational managers with the vision and desire for quality SE was a vital prerequisite for achieving the goal of building and maintaining the standards of SE in schools. Most respondents were in agreement that achieving high quality SE was not an easy task, one policy maker said "as important as it is, quality SE requires inspirational, enthusiastic, and committed people to develop educational programmes 
that can provide learning with superior academic experiences". While science alumni focused on the need to have responsible leaders who wanted change in the way SE was delivered in schools, teachers considered effective and competent educational management as bedrock towards better successes in the delivery of quality SE. Most respondents wanted effective leaders and managers who would help to manage learners' knowledge development, nurturing the instructional programmes and school culture, and ensure learning objectives in science were met.

xiii. Good science teachers. More than $80 \%$ of respondents shared the view that good teachers were important components for quality SE. Good teacher were identified as possessing the following attributes: being well trained, having appropriate subject matter knowledge, having the motivation to teach, and being experienced. Most respondents felt that quality SE was only possible if teachers were kind, wanted to teach, were patient, caring, and friendly, passionate about teaching, committed to the profession, resilient, and felt deeply about being responsible for their students' learning. For most respondents the teacher related challenges were felt as the most significant barriers to realising the vision of providing quality SE in Tanzanian JSS.

In view of these varied labels for quality SE, the concept of quality SE is generally described in terms of the investment and consumption value of SE, and how such benefits are distributed across a diversity of stakeholders. The investment component entails the monetary, material and human resource investment; its consumption value includes aspects such as learners' educational outcomes, the social value of SE, the ultimate role of SE on individuals' economic lives, ability of SE to meet the demands of its stakeholders and the expectations of good educational achie vement, all of which are accrued as returns of SE among learners after their graduation. The diversity of views regarding quality SE presents a challenge of what would be the appropriate ways to define and understand quality SE. The discussion of that follow identifies the controversial areas for describing quality SE and the way forward.

\section{Discussion}

While recognizing the diversity of views among SE stakeholders regarding the concept of quality SE, the respondent's views also reveal some tensions and controversies that need to be resolved for the full realisation of a quality SE system in Tanzania. These controversies include: contestable approaches for understanding quality SE, debatable measures for quality SE, and differing goals for quality SE. The details of these controversies are discussed in the sections that follow.

\subsection{Contestable Approaches for Understanding Quality SE}

The findings of the present study echoed five major approaches that the respondents used to describe the concept of quality SE. The approaches identified were similar to those propounded by Curtis and Boultwood (1968) and UNESCO (2004), including humanistic, behaviouristic, critical, indigenous and pragmatic approaches. 


\subsubsection{Humanist Approach}

Quality SE within the tradition of humanist theory can be interpreted as the extent to which learners translate learning into social action. Similar to the perspective by Khatib, Sarem, and Hamidi (2013), respondents to this study viewed quality SE as the extent to which graduates meet 'absolute' criteria concerning, for example, academic achievement, attitudinal change, scientific and technological achievements, and improvement of students' behaviour and values. Most respondents, especially students and parents, judged quality SE by its ability to develop an individual learners' potential.

\subsubsection{Behaviourist Approach}

In behaviourist theories, quality SE can be judged through standardised, externally defined, and controlled curricula, based on prescribed objectives that are defined in the learner (Curtis $\&$ Boultwood, 1968). This view was clear within the curricular materials that were analysed whereby a behaviouristic view of quality SE was evident. For example, quality SE in the documents was mirrored by the emphasis on students being led and their behaviour controlled for specific ends. Teachers mostly assumed the role of managers of students' behaviour and therefore became the key players for quality learning.

\subsubsection{Critical Approaches}

Quality SE within the tradition of critical theory can described as a tool for prompting social change, encouraging critical analysis of social power relations and ensuring that learners participate actively in their learning (Freire, 1985; Goodman, 2005), thus freeing the $m$ from externally defined needs and helping them to explore alternative ways of thinking that may not have blossomed under dominant norms (McLaren \& Farahmandpur, 2003). The findings of this study reflected elements of these approaches, in that they challenged the way SE was enacted by demanding a change to the way SE was planned, practiced, evaluated and monitored.

\subsubsection{Indigenous Approaches}

In indigenous approaches, quality SE can be described as an emancipatory tool from the legacies of colonial educational frameworks (Dei, 2012). The respondents revealed a critical demand for setting the importance of SE's relevance, context responsiveness, and functionality to the socio-cultural circumstances of both the nation and the learner, as well as to ensuring that the local design of curriculum content, pedagogies, and assessment procedures were relevant to the learner. The respondents' points of views are similar to the prominent examples of anti-colonial movements in education pioneered by Mahatma Gandhi (India), Julius Kambarage Nyerere (Tanzania), and Archbishop Desmond Tutu (South Africa) (Tutu, 2000).

\subsubsection{Pragmatic Approach}

A pragmatic approach views quality SE as a lifelong process where education is considered to be the constant reconstruction or re-organisation of experiences to meet the challenges of the present world (Dewey, 1938). Similar to Biesta and Burbules (2003) and Fontrodona (2002) 
the findings of the present study revealed that most respondents supported the idea that education should connect school experiences with learners' real life experiences, emphasize on utilitarianism of science knowledge, and emphasise on applicability of science knowledge.

The array of these approaches portrays the existence of conflicting views among the stakeholders towards quality SE. It is clear from the findings that while some respondents addressed quality SE in terms of its virtue or in relation to achieving a better life, others described it in relation to intellectual, behavioural and attitudinal change. Such a varied understanding has resulted in dilemmas over whether or not quality SE should be directed at things useful in life, or to those factors conducive to the community's needs. This situation presents a challenge in building a consensus in understanding the concept of quality SE.

Such a challenge is likely to be addressed by pragmatic perspective, because pragmatism is a comprehensive and inclusive perspective that is able to combine diverse approaches towards producing a harmonised and common consensus for promising approaches in understanding quality SE (Rosenthal \& Thayer, 2011). The suggestion to adapt a pragmatic approach is based on the fact that there is no one approach that can claim to be satisfactory on its own in understanding the concept of quality SE, because quality SE is multifaceted, illusive, and value laden (Sallis, 2002). Through pragmatism, the various approaches echoed in the respondents' views can be brought together and harmonised in the process of understanding quality SE (Haack, 2006; Tröhler \& Oelkers, 2005).

\subsection{Debatable Measures for Quality SE}

The literature indicates that for a number of decades there has been no authentic way to measure quality education (UNICEF, 2000). Common questions revolving around the concept of quality measures have included: how can we appropriately measure quality education? Is it enough to use an input-process-output model as a criterion to measure the quality of education? Can a single model be enough to be used in measuring the quality of education anywhere in the world? (Kesidou \& Roseman, 2002; Sifuna, 2007).

In an attempt to describe how to judge the quality of SE, the respondents' voices echoed a variety of views on how to measure quality SE. These views include:

i. Measuring quality SE by looking at the relationship between various educational inputs and student performance (output). The findings have identified a wide variety of SE inputs including: An availability of good educational infrastructure and resources, a quality schooling environment, textbooks, quality teachers, a relevant curriculum, quality educational policy, good learning support services, good educational management and leadership plans, appropriate collaboration processes in the education sector, conducive learning environments, attention paid to students' physical well-being, and good family involvement in educational matters. The outputs involved students' results on various assessments and/or end-of-cycle examinations. Though this approach might be useful in identifying the inputs that are associated with desired quality SE outputs, Lockheed and Verspoor (1991) and Muskin (1999) have argued that the approach seems to neglect the micro-educational processes at the 
school, classroom, and community levels from which the aforementioned inputs are processed to create the desired educational outputs.

ii. Measuring quality SE by looking at the efficiency of the education system (i.e., the efficiency of both the internal and external system). The internal system's efficiency have been described in the findings as including aspects such as the students' enrolment, completion, drop-out, and repetition rates. The external system's efficiency was measured by looking at the outcomes of education or the productivity of school leavers. Similar to Scheerens' (2002) view, the respondents related education outputs to the employability of the graduates, the possession of relevant skills and knowledge among graduates, usefulness of the graduates in society, and a change of economic status of the individual learner after graduation.

iii. Measuring quality SE by looking at the way the content, context, and culture of a particular place are reflected in education processes. Some respondents judged the quality of SE by using the degree to which SE content was responsive and relevant to the Tanzanian culture and the targeted public who were the final beneficiaries.

iv. Measuring quality SE by looking at the efficiency of educational processes from which inputs were transformed into outputs. These processes included teaching and learning practices at the school level, interaction within the schools, interaction between the school and the community, accountability and responsibility among school staff members. The identified a concern about ways in which the inputs interacted at the school level to produce quality learning experiences, as well as the manner in which inputs were processed to produce the expected outputs.

v. Measuring quality SE by judging its ability to achieve the national goals of education. In this respect the findings identify quality SE system being measured by its consistency in achieving the goal of providing the equivalent educational experiences needed by the public to meet challenges in the new era of science and technology. The finding also identified that quality SE was measured not only in terms of the availability of quality checking mechanisms in education but also in the availability of a strong inspection practice for determining whether national challenges could be solved via schooling experiences.

vi. Measuring quality SE in terms of cross-national comparative studies of student achievement. Some respondents, especially science alumni, measured quality SE in terms of its rank as rated by the Programme for International Student Assessment (PISA) the International Association for the Evaluation of Educational Achievement (IEA), the Trends in International Mathematics and Science Study (TIMSS) and the Progress in International Reading Literacy Study (PIRLS), all of which measure the quality of education by comparing students' performance across different countries.

The view towards appropriate measures for quality SE was identified by the findings of this study to be varied and conflicting. In fact most respondents' views revealed a critical question as to whether or not present practices acclaimed as measures for quality SE can technically be 
adequate in measuring the quality of SE anywhere in the world and whether they can effectively respond to the actual situation of education processes for any context and cultural background.

It is argued in this study that bringing all the views together to form a grand design measure could be more useful than using a single measure as the only lens to judge quality SE experiences in schools. Bringing the diverse measures for quality SE is likely to maximize the possibility of assessing all aspects of learning in science. In line with this argument, UNICEF (2000) suggests that to achieve a fair quality measure there is a need to use a variety of information to judge the effects of education services in schools. This recommendation is important in SE development because the possibility of providing quality education in any education system depends on the ability to appropriately measure it (Hakielimu, 2007; Mosha, 2000; Sifuna, 2007). However the success towards appropriate measuring of quality SE is also dependent on the nature of the countries' policies, educational missions, visions, targets, technology in use, and the composition of groups of stakeholders (TEN/MET \& Oxfam, 2006).

It is crucial to consider that the important concern in selecting the approach for judging the quality of $S E$ is not by focusing on whether or not such practices emphasise inputs, processes, or outcomes as criteria for judging quality of SE; what matters is whether the selected measures consider a variety of information from different sources in making judgments about the effectiveness of educational practices. To achieve either explicit or implicit goals, an agreement across stakeholders on a single model for measuring quality SE is a huge challenge. However, efforts can be harnessed to get a comprehensive grand design, which could be used to provide a picture of the overall trend of quality SE in Tanzanian JSS. Again this paper proposes a shift to pragmatic frameworks which are likely to offer a means for encouraging multiple approaches towards what works best rather than limiting the judgment of quality SE to testing or a single measurement; a situation which has the potential to disadvantage the learners and thwart their hopes and expectations for pursuing further science studies.

\subsection{Varied Goals for Quality SE}

Debates about the need for quality SE in the twenty-first century have recently escalated interest in internationally (Goodrum et al, 2001; Tytler, 2007). The variety of goals for quality SE have not only introduced confusion and controversy in SE discourses, but have also raised challenges regarding the targets for quality SE (Malekela, 2000; Mosha, 2000). The findings of this study revealed a wide array of goals for quality SE that were considered as being indicative of quality SE. These include:

\subsubsection{Winning the Global Competition}

These new initiatives have raised interests in improving quality SE to match the global competition in resource production and service delivery (Bybee \& Fuchs, 2006; Osborne, 2006). The findings revealed that one of the major goals for having quality SE was for winning the global struggle as an important achievement which was only possible through 
ensuring excellence in education systems and their outputs. This goal line shows that education sectors are therefore confronted with the challenge of changing old practices and educational procedures to accommodate technological advances and compete globally (Bull, et al., 2010; Gluckman, 2011).

\subsubsection{Fulfilling the Stakeholders' Right to Quality SE}

The findings also revealed another goal for quality SE which includes a stakeholder satisfaction and fulfilment of the right to a quality education are reasons for improving quality education. The findings also show that the respondents though differed in their views, but they were highly conscious of their right to achieve value for money that was invested in schools and that the schools had to fulfil their responsibilities in providing quality SE, a situation which would ensure that students receive their deserved right of quality SE experiences and positive outcomes for the time spent in schools.

\subsubsection{Achieving and Maintaining Standards}

The findings of this study also mirrored the global need to improve quality SE so as to meet the challenges of developing scientifically literate citizens as well as meeting global market demands. Drawing from the Tanzanian current experiences, the standards for quality SE are locally set and efforts are then organised to meet those standards. This situation suggests that as long as there is a difference in context, culture, and goals for education, it is difficulty to have universal and common goals for quality SE.

\subsubsection{Increasing the Credibility, Prestige and Status of Education Systems}

The findings reveal that one of the major reasons for providing quality SE in Tanzania is achieving consistency with leading practices in the world, by raising the status of educational outputs and the production of the brand value of educational output. The respondents, especially parents, had a feeling that by achieving high quality SE, learners would be guaranteed assurance of employment, a good life, and monetary stability. This view neglects an education system's vital accountability to address stakeholders' needs, contextual challenges, and to meeting public interests. This diversion of emphasis leads to directing all efforts to improve the system for the sake of the system itself, a situation which presents another uncertainty as to whether raising the status quo, the image and reputation of the education system, would actually be associated with good SE outcomes.

The analysis of a range of respondents' views about quality SE as discussed earlier reveals a number of influences, including the category of stakeholders involved in the study, the cultural background of these stakeholders, the context in which quality as an educational aspect is described, the technology currently in use, the era under which a specific definition is given and global views on quality SE. But again, data reveals that the way quality SE is conceptualised is rapidly evolving over time and is likely to have different emphasis in different nations, education sectors, cultures and among different players in the education system (i.e., students, teachers, policymakers, business communities, and other local actors).

It is evident in the findings that respondents differ in the way they describe and measure 
quality SE. This difference could be attributed to their occupations (as educators), educational exposure, and the era in which such conceptualisations are formed, all of which ultimately shape their beliefs about quality SE. Similarly to studies conducted by Sifuna (2007), Thomas (2003), and Tikly \& Barrett (2007), it was also evident in these findings that what is considered quality in one country might be different to the one made in another country, due to differences in context, culture and stakeholder composition.

In a country such as Tanzania, where colonial burdens are still reflected in existing education frameworks, there is a need to shift towards pragmatic approaches in understanding and addressing the concept quality SE. The shift to pragmatic perspectives is likely to provide a platform for harmonising diverse conceptions about the concept across different educational key players. The use of this new focus towards quality SE together with input - process output model by OECD (2003) and Scheerens (2002) depicts a changing approach towards producing a strong, quality and relevant SE system.

The difference in perspectives among these groups, as identified earlier in this paper, aligns with the persistently elusive nature of the term 'quality education' as propounded by Sallis (2002), its multi-faceted nature by Fraser (1994) and its slippery and value-laden nature by Harvey and Green (1993). Given the pragmatic implications of these diverse views and controversies towards quality SE, there is a need for SE to concentrate on emphasis of aspects that directly touch learners' daily lives. In the context of this paper, the findings echoed several common areas of concentration for quality SE which the researcher considers to be important. These areas of emphasis include providing quality SE: for individual survival, for individual protection against discrimination and insecurity, for individual development (cognitively, psychologically and affectively), for active participation and empowerment in decision making, for individual and social promotion (economically, socially, and culturally), and for satisfaction or meeting individual interests and desires. These aspects are summarised as the $\boldsymbol{S}^{2} \boldsymbol{D P} \boldsymbol{P}^{3}$ model for developing quality SE. The model is created by taking the highlighted letter of each quality dimension in Table 2 .

Table 2. The elements of " $\mathrm{S}^{2} \mathrm{DP}^{3}$ model" for quality $\mathrm{SE}$ in Tanzania

\begin{tabular}{|c|c|}
\hline $\begin{array}{l}\text { Quality } \\
\text { dimension }\end{array}$ & Quality indicator \\
\hline Survival & $\begin{array}{l}\text {-Emphasis of skills in demand by the job market and the community at large. } \\
\text {-Opportunities for learners to build their own know ledge by combining indigenous and } \\
\text { external elements. }\end{array}$ \\
\hline Satisfaction & $\begin{array}{l}\text {-Opportunities for fulfilling the stated or implied needs of the stakeholders and adding } \\
\text { up to the customers' satisfaction, meeting or/and even exceeding the stakeholders' } \\
\text { requirements and expectations. } \\
\text {-Opportunities for satisfying the learners' interests, meeting their desires and providing } \\
\text { a conducive environment that nourishes and nurtures learners' passion for science. } \\
\text {-Opportunities for achieving the stipulated education aims, goals and requirements of } \\
\text { interest groups in education. }\end{array}$ \\
\hline
\end{tabular}


Development -Opportunities for students to develop to the fullest potentials in terms of cognitive, emotional, and creative capacities.

-Opportunities for developing learners within the ir professional expectations, preferred professional identities, and person they desire to become in the future.

-Emphasis on schools' enhancement and students' empowerment, with students learning competencies and skills required for developing individual identity.

Protection -Assurance of development of learners' attitudes free from discrimination, where all have equal opportunities to develop themselves, their families, and their communities.

-Presence of support objectives of peace, social responsibility and security.

Participation -Opportunities for involvement of diverse categories of stakeholders in decision matters related to the nature, structure, processes and the outcomes of their schools' SE. -Opportunities for students to be involved in broad range of work and community activities that affect the quality of their lives and of those around them.

-Presence of mutual respect, shared power and authority in matters concerning education.

Promotion -Emphasis of individual and social promotion economically, socially, and culturally as a result of schooling.

-Emphasis on students' employability, assurance of good future prospects, and graduates' productivity in the society.

-Opportunities for promoting equality and equity, with recognition of the cultural diversity surrounding the education arena.

\section{Conclusion}

No subject has been so widely discussed in the literature as quality issues in education. Striking at the heart of its existence, critical comments about quality SE have been identified in this paper raising concerns about expectations. The form of this conversation has been to debate whether quality SE is "illusive," "slippery," and /or value laden. The findings in this paper suggest that, the concept of quality SE may be even more challenging to define if limited key players are involved in delineating its meaning, indicators, and importance. It is argued in this paper that harnessing different thoughts and harmonising them is an important challenge that Tanzanians need to overcome to generate an agreed definition of quality SE. This process could maximise the possibility of bringing the ownership of education practices into the hands of all stakeholders. This could also make every educational stakeholder feel accountable for educational outcomes and trigger a sense of responsibility, dedication, and conviction among stakeholders to improve quality SE in their JSS. This is possible if frameworks such pragmatism is used as a theoretical lens to define what is worth learning in science. As argued in this paper, a pragmatic perspective would bring together differing perspectives and judge them in terms of their functionality and context responsiveness, workability, sustainability, and usefulness in defining the positive outcomes of quality SE.

Related to this these views, the findings in this paper do don't identify quality SE as "new concept in education" but an educational conceptual concern that reinforces a slanted use of 
terms, and creates a diverse and controversies in practice. At other times, critics about quality literature present a baffling list of different types of designs with unusual names, labels and brands about quality education. This study has presented critical comments about quality SE and the controversies that exist around its meaning, measurement, and importance in Tanzanian JSS. The position taken in this paper is that science educators and researchers need to squarely place the controversies about quality SE on the table for discussion, honour their presence, and plan to solve them using a pragmatic perspective, as this worldview uses a multiplicitous paradigm of dialectic approaches, which would likely help to address the concept of quality SE as effectively as possible.

Using a pragmatic approach it is also possible to accommodate most conceptualisations of quality SE by harmonising their differences and deploying their specific usefulness in presenting a comprehensive, inclusive, flexible and useful model for understanding the concept of quality SE. This could involve the combination of different approaches to address the concept of quality education and thus providing a better understanding of the concept. This argument is based on the idea that each view towards quality SE when applied singly has its own limitations, which could be addressed by deploying another approach concurrently.

It is expected that the discussion in this analysis will provide vital information from all SE stakeholders about the present view regarding its meaning, measurement and perceived goals in Tanzanian educational system. In an attempt to have a grand design for quality SE, it should be understood that:

1. Providing quality SE is a joint task that involves a number of stakeholders who are likely to have different views on how to approach it;

2. An attempt to understand and describe quality SE with a single line of evidence and explanation is unrealistic. Therefore cumulative evidence from a variety of sources is commendable;

3. The availability of financial, human, material and physical resources can directly influence community involvement, student engagement, and teacher motivation in the provision of quality SE, which is likely to lead to the improvement of students' performance;

4. Without clear and relevant philosophy and policy to provide effective guidelines on how to provide excellent learning experiences in schools, the achieve ment of quality $\mathrm{SE}$ is unlikely;

5. Without relevant curriculum; effective assessment procedures; quality science teacher preparation, and development and retention, adequate pedagogy in SE is difficult to achieve.

6. Broader consultation in the rebranding process of SE by including; policy makers, curriculum developers, educators, parents, students, the business community and other local actors; and the wider consideration of stakeholder characteristics such as 
occupation, education exposure, cultural background, the contextual pressures and the technology available and in use is commendable;

7. Increasing attention to the present contextual and global challenges that define what is worthy learning in science, the relevance, context responsiveness, functionality and applicability of the SE experiences is necessary.

Assuming that quality SE researchers look at this diversity of views and controversies regarding quality SE seriously (an assumption that several writers have questioned (see Sifuna, 2007, Sallis 2002, Fraser 1994, and Harvey and Green 1993); the researcher considers the discussion in this paper as an important conversation in the SE literature. As a pragmatist, the researcher is confidently interested in the consequences of this discussion of controversies, while hoping that most other researchers will be interested by showing their commitment to solving the controversies now being raised.

\section{Acknowledgments}

I am grateful for the interview participants in study for taking the time to talk with me. Appreciation also goes to all the friends and peer readers who helped in shaping the structure of the paper.

\section{References}

Biesta, G. J. J., \& Burbules, N. (2003). Pragmatism and Educational Research. Lanham, MD: Rowman and Littlefield.

Bull, A., Gilbert, J., Barwick, H., Hipkins, R., \& Baker, R. (2010). Inspired Science: A paper commissioned by the Royal Society and the Prime Minister's Chief Science Advisor. New Zealand Council for Educational Research.

Bybee, R. (2010). The Teaching of Science: 21st-Century Perspectives. Arlington, VA: NSTA Press.

Bybee, R. W., \& Fuchs, B. (2006). Preparing the 21st century workforce: A new reform in science and technology education. Journal of Research in Science Teaching, 43(4), 349-352.

Chonjo, P. N., Osaki, K. M., Possi, M., \& Mrutu, S. (1996). Improving Science Education in Secondary Schools: A Situational Analysis of Selected Government Secondary Schools in Tanzania Mainland. Dar es Salaam, Tanzania: Ministry of Education and Culture.

Curtis, S. J., \& Boultwood, M. E. A. (1968). A Short History of Educational Ideas. London, University Tutorial Press.

Dei, G. J. S. (2012). Indigenous anti-colonial knowledge as 'heritage knowledge' for promoting Black/African education in diasporic contexts. Decolonization: Indigeneity, Education \& Society, 1(1), 102-119.

Dewey, J. (1938). Logic: The Theory of Inquiry. New York: Carbondale, IL: Southern Illino is University Press. 
Fontrodona, J. (2002). Pragmatism and Management Inquiry. New York: Quorum Books.

Fraser, B. J. (1994). Research on classroom and school climate. In D. Gabel (Ed.), Handbook of Research on Science Teaching and Learning (p.493-541). New York: Macmillan.

Freire, P. (1985). The Politics of Education: Culture, Power and Liberation. (D. Macedo, Trans.). South Hadley: Bergin and Garvey.

Galabawa, J. C. J. (1994). Status and future challenges of the Tanzania primary and secondary education. In L. A. Msambichaka, H. P. B. Moshi, \& F. P. Mtatifikolo (Eds.), Development Challenges and Strategies for Tanzania: An Agenda for the 21stcentury (pp. 291-306). Dar es Salaam: Dar es Salaam University Press.

Gluckman, P. (2011). Looking Ahead: Science Education for the Twenty-First Century. A paper commissioned by the Royal Society and the Prime Minister's Chief Science Advisor. New Zealand Council for Educational Research.

Goodman, R. (Ed.) (2005). Pragmatism: Critical Concepts in Philosophy. London: Routled ge.

Goodrum, D., Hackling, M., \& Rennie, L. (2001).The Status and Quality of Teaching and Learning of Science in Australian Schools: A Research Report. Canberra: Department of Education, Training and Youth Affairs.

Green, D. (1994). What is quality in higher education? Concepts, policy and practice. In D. Green (Ed.), What is Quality in Higher Education? SRHE and Open University Press, Buckingham.

Haack, S. (Ed.) (2006). Pragmatism, Old and New. Amherst NY: Prometheus.

Hakielimu. (2007). Redefine quality education in Tanzania. From input to capabilities. Working Paper. October, 2007. Dar es salaam.

Hamilton, M., Mahera, W. C., Mateng'e, M. F. J., \& Machumu, M. M. (2010). A needs assessment study of Tanzania science education. The Economic and Social Research Foundation (ESRF), Dar es Salaam.

Harvey, L., \& Green, D., (1993). Defining quality. Assessment and Evaluation in Higher Education, 18(1), 9-34.

Kesidou, S., \& Roseman, J. E. (2002). How well do middle school science programmes measure up? Findings from Project 2061 's curriculum review, Journal of Research in Science Teaching, 39(6), 522-549.

Khatib, M, Sarem, S.N., \& Hamidi, H. (2013). Humanistic education: Concerns, implications and applications. Journal of Language Teaching and Research, 4(1), 45-51.

Kitta, S. (2004). Enhancing Mathematics Teachers' Pedagogical Content Knowledge and Skills in Tanzania. Doctoral dissertation. Enschede: University of Twente.

Knipprath, H. (2010). What PIS A tells us about quality and inequality of Japanese education in mathematics and science. International Journal of Science and Mathematics Education, 9, 
389-408.

Lockheed, M. E., \& Verspoor, A. M. (1991). Improving Primary Education in Developing Countries. Oxford, Oxford University Press for the World Bank.

Mafumiko, F. (2004). Micro-Scale Experimentation as a Catalyst for Improving the Science Curriculum in Tanzania. Doctoral Thesis University of Twente. Enschede.

Malekela, G. (2000). Quality of secondary school education in Tanzania. In J. C. J. Galabawa, F. M. K. Senkoro, \& A. F. Lwaitama (Eds.), The Quality of Education in Tanzania: Issues and Experiences. Faculty of Education, University of Dar es Salaam.

McLaren, P., \& Farahmandpur, R. (2003). The globalization of capitalism and the new imperialism: notes towards a revolutionary critical pedagogy. In D. Carlson, \& G. Dimitriad is (Eds.), Promises to Keep: Cultural Studies, Democratic Education and Public Life (pp. 39-76). New York and London: Routledge Falmer.

MoEC. (2004b). Secondary Education Development Plan. Dar es Salaam: United Republic of Tanzania.

Mosha, H. J. (2000). Conceptualizing quality education. In J. C. J. Galabawa, F. M. K. Senkoro, \& A. F. Lwaitama (Eds.), The quality of Education in Tanzania: Issues and Experiences. Faculty of Education, University of Dar es Salaam.

Motola, S. (2001). Quality and indicators of quality in South African education: a critical appraisal. International Journal of Educational Development, 2-78.

Munro, M., \& Elsom, D. (2000). Choosing Science at 16. NICEC project report, NICEC, Cambridge.

Mushashu, B. (2000). The issues of quality of public secondary schools: What ought to be done? In J. C. J. Galabawa, F. M. K. Senkoro, \& A. F. Lwaitama (Eds.), The Quality of Education in Tanzania: Issues and Experiences. Faculty of Education, University of Dar es Salaam.

Mushashu, B. K. (1997). Quality of education in public secondary schools: Major problems and solutions. Paper Presented at the Conference on Quality of Education in Tanzania. Arusha.

Muskin, J. A. (1999). Including local priorities to assess school quality: The case of Save the Children Community schools in Mali. Comparative Education Review, 43(1), 36-63.

OECD. (2003). Education at a Glance: OECD Indicators. Paris: OECD. Organisation for Economic Co-operation and Development -Global Science Forum.

OECD-GSF. (2006). Evolution of Student Interest in Science and Technology Studies Policy Report. OECD: Paris.

Ogunmade, O. T. (2005). The Status and Quality of Secondary Science Teaching and Learning in Lagos State Nigeria. PhD Thesis, Edith Cowan University, Perth Australia. 


\section{Macrothink}

Issues in Social Science ISSN 2329-521X 2015, Vol. 3, No. 1

Ogunniyi, M. B. (1986). Two decades of science education in Africa. Science Education, 70(2), 111-122.

Osaki, K. (1994). Indigenous African knowledge, understanding the use and misuse. A Paper Presented at Pan African Colloquium on Education Innovations in Post-Colonial Africa. Cape Town.

Osaki, K. (1995). Issues in Teaching and Learning of science in Tanzania. Unpublished paper UDSM.

Osaki, K. (2002). Science Education Research and Teacher Development in Tanzania. Amsterdam. VrijeUniversiteit Printers.

Osaki, K. M., \& Tilya, F. (Eds.) (2004c). Science and Maths Education. Publication Series (No. 1). Dar es Salaam: University of Dar es Salaam.

Osaki, K., Hosea, K. \& Ottevanger, W. (Eds.) (2004). Reforming Science and Mathematics Education in Sub-Saharan Africa: Obstacles and Opportunities. Dar es Salaam: TEAMS, University of Dar es Salaam.

Osaki, K., Ottevanger, W., Uiso, C. \& van den Akker. J. (Eds.) (2002). Science Education Research and Teacher Development in Tanzania. Amsterdam: Vrije Universiteit. Salaam.

Osborne, J. (2006). Communicating Science: A BAI Round Table Summary. The Centre for Informal Learning and Schools. [Online] Available: www.exploratorium.edu/cils/documents /RTcommunicationJO.pdf

Ottevanger, W., Osaki, K., \& van den Akker. J. (2005). The TEAMS project in Tanzania: From intervention to capacity building. CICE Hiroshima University, Journal of International Cooperation in Education, 8(1), 111-123.

Rosenthal, S. B., \& Thayer, H. S. (2011). Pragmatism. In Encyclopaedia Britannica. [Online] Available: http//www.britannica.com/EBchecked/topic/473717/pragmatism

Roth, W.M., \& Lee, S. (2004). Science education as/for participation in the community. Science Education, 88(2), 263-291.

SACMEQ. (2005). The SACMEQ II project in Malawi: A study of the conditions of schooling and the quality of education. Working Report. Malawi.

Sallis, E. (2002). Total Quality Management in Education. Psychology Press.

Scheerens, J. (2002). School self-evaluation: Origins, definition, approaches, methods and implementation. In D. Nevo (Ed.), School-based Evaluation: An International Perspective (pp. 35-73). Oxford: Elsevier Science

Sifuna, D. (2007). The challenges of increasing access and improving quality: An analysis of Universal Primary Education intervention in Kenya and Tanzania since 1970s. International Review of Education, 53, 68-699.

Sumra, S., \& Rajani, R. (2006). Secondary education in Tanzania: Key policy Challenges. A 


\section{Macrothink}

Issues in Social Science ISSN 2329-521X 2015, Vol. 3, No. 1

Working Paper on the Norwegian Post- Primary Education Fund for East Africa (NPEF). Oslo.

TEN/MET., \& Oxfam. (2006). Quality Education Conference Kunduchi Declaration. Dar es Salaam: TEN/MET/Oxfam.

Thomas, H. (2003). The arguments for and the meaning of quality. ELT Journal, 57(3), 234-241.

Tikly, L. (2010). A roadblock to social justice? An analysis and critique of the South African education Roadmap. International Journal of Educational Development, 31(1), 86-94.

Tikly, L., \& Barrett, A. M. (2007). Education Quality. Research Priorities and Approaches in the global era. Bristol: University of Bristol.

Tröhler, D., \& Oelkers, J. (Eds.). (2005). Pragmatism and Education. Rotterdam: Sense Publishers.

Tutu, D. (2000). The Art of Peace: Nobel Peace Laureates Discuss Human Rights, Conflict and Reconciliation (pp. 93-113). New York: Snow Lion.

Tytler, R. (2007). Re-imagining Science Education - Engaging Students in Science for Australia's Future. Camberwell Vic: Australian Council for Educational.

UNESCO. (2004). Education for All, the Quality Imperative. EFA Global Monitoring Report 2005. Paris, UNESCO.

UNESCO. (2005). EFA Global Monitoring Report 2005: Education for All, the Quality Imperative. Paris: UNESCO.

UNESCO. (2008).The Global Literacy Challenge. Paris, Unesco.

UNICEF. (2000). Defining quality in education. A paper Presented by UNICEF at the Meeting of the International Working Group on Education. Florence, Italy 